\title{
DIMENSI PASTORAL DALAM DOA: \\ MENEMUKENALI PRAKTIK DOA YANG BERTANGGUNGJAWAB \\ DALAM PELAYANAN PENDAMPINGAN \\ DAN KONSELING PASTORAL
}

\author{
Besly J. T. Messakh \\ Sekolah Tinggi Filsafat Theologi Jakarta \\ messakhbesly@gmail.com
}

\begin{abstract}
Looking from a pastoral care and counseling perspective, prayer as a ritual is a human response for God's action. As a response, prayer presupposes a responsible communication with God as absolute authority in one's life. If the communication running well, the pastoral function of prayer as a ritual enhance people well-being mentality and spirituality. Therefore, when doing pastoral care or pastoral counseling, pastoral caregiver needs to make sure that people have healthy communication with true God as the Ultimate Absolute Authority. For those reasons, a pastoral caregiver should understand about the theological principle in praying and have ability to use prayer as pastoral means for themselves and people who need their pastoral ministry.
\end{abstract}

Keywords: care; church; counseling; pastoral; prayer

\section{Pendahuluan}

Persoalan tentang penting tidaknya doa dalam pendampingan pastoral atau konseling pastoral—sebagai salah satu bentuk dari pendampingan pastoral ${ }^{1}$ — seringkali $^{-}$ menjadi pokok perdebatan yang sebenarnya tidak berdasar di kalangan para pelaku pelayanan pastoral, karena doa merupakan unsur penting yang perlu dimanfaatkan secara bertanggungjawab dalam konteks pendampingan dan konseling pastoral sehingga melalui doa mereka yang dilayani dapat memahami dan memiliki sikap yang tepat untuk mengatasi masalah yang sedang dihadapi.

\footnotetext{
${ }^{1}$ Ketika mempercakapkan berbagai jenis pelayanan pastoral, David G. Benner menyebutkan bahwa pelayanan pastoral dalam gereja berlangsung dalam konteks persahabatan warga gereja. Dalam konteks persahabatan, maka semua tindakan pelayanan gereja dapat diberi perspektif pastoral sehingga tindakan pelayanan seperti ibadah dan lain-lain, dapat disebut sebagai pelayanan yang berspektif pastoral. Inilah yang oleh Benner disebut sebagai pelayanan pastoral. Selanjutnya, dalam melakukan pelayanan pastoral, tentu ada kebutuhan untuk mendampingi orang-orang secara pribadi atau kelompok tertentu yang berlangsung secara informal dan tidak terstruktur. Menurut Benner ini disebut sebagai pendampingan pastoral. Akhirnya sebagai penajaman dari pendampingan pastoral, terdapat tindakan pelayanan pastoral yang disebut konseling pastoral serta bimbingan spiritual. Konseling pastoral dan bimbingan spiritual dilakukan secara formal dan lebih terstruktur, dimana orang-orang yang mendampingi pribadi mengetahui kelompok yang perlu didampingi memang memiliki kecakapan khusus dalam hal melakukan pelayanan dimaksud.
} 
Merle Jordan mengatakan bahwa perdebatan yang dimaksud itu dapat dinamakan sebagai perdebatan di antara para pelaku pelayanan pastoral yang berpandangan konservatif melawan mereka yang berpandangan liberal ${ }^{2}$. Menurutnya, pelaku pelayanan pastoral yang berpandangan konservatif sangat menekankan pentingnya doa sebagai ritual dalam pendampingan dan konseling pastoral karena mereka yakin bahwa melalui doa, Allah secara langsung campur tangan dalam memulihkan atau menolong orang-orang bermasalah yang didampingi secara pastoral ${ }^{3}$.

Sementara itu, mereka yang berpandangan liberal justru kurang, bahkan tidak melihat manfaat doa sebagai ritual dan juga sumber-sumber rohani lainnya dalam pelayanan konseling pastoral. Bagi mereka doa hanya pelengkap yang ditambahkan ke dalam konseling pastoral karena sesuai pengertiannya pelayanan konseling merupakan jenis pelayanan yang dilakukan atas nama gereja. Rasanya kurang pantas jika dalam pendampingan atau konseling pastoral yang dilakukan atas nama gereja, tidak ada unsur Doa di dalamnya ${ }^{4}$. Oleh karena itu, Bruce Evenson et.al ketika mengomentari tentang bagaimana doa telah digunakan dalam praktik pendampingan pastoral terhadap orang sakit, di kalangan para pelaku pelayanan pastoral yang oleh Jordan disebut sebagai orang-orang yang berpandangan liberal, mengatakan:

Setiap kali, doa merupakan bagian otomatis yang harus ada dalam kunjungan pelayan gereja bagi orang sakit. Setiap kunjungan mesti diakhiri dengan doa atau dengan janji untuk berDoa bagi yang sakit di gereja (atau sinagoga). Meskipun doa merupakan bagian dari perkunjungan, seringkali doa justru tidak kena mengena dengan emosi ataupun isi dari kunjungan tersebut. Doa adalah ritual tambahan yang menjadi bagian dari kunjungan tetapi tidak merupakan bagian dari pendampingan pastoral ${ }^{5}$.

Perdebatan tersebut juga dilihat dan dikomentari oleh George M. Furniss. Dalam hal ini Furniss berpendapat bahwa bagaimanapun doa tetap menjadi penting dan diperlukan dalam pendampingan dan konseling pastoral. Pandangan ini pada prinsipnya sejalan dengan pandangan para pelaku pelayanan pastoral yang oleh Jordan disebut sebagai mereka yang berpandangan konservatif. Namun, pada saat yang sama Furniss juga mengkritik model-model pedekatan doa di kalangan para pelaku pelayanan pastoral yang berpandangan konservatif yang menurutnya tidak efektif dalam memanfaatkan doa sebagai

\footnotetext{
${ }^{2}$ Merle Jordan, Prayer and Meditation in Pastoral Care and Counseling, Dalam Handbook for basic Types of Pastoral Care and Counseling, peny. Howard W. Stone dan William M. Clements, (Nashville: Abingdon Press, 1991), 129.

${ }^{3}$ Ibid, 130 .

${ }^{4}$ Ibid, 129.

${ }^{5}$ Bruce Evenson. et.al, Prayer and Pastoral Care, The Caregiver Journal, (2014): 40.
} 
sarana pendampingan atau konseling pastoral karena kurang memperhitungkan perspektif ilmu psikologi dalam praktik pelayanan doa yang dilakukan. Padahal bagi Furniss pelayanan doa yang setia pada tradisi Alkitab adalah pelayanan doa yang juga sungguhsungguh memperhitungkan perspektif ilmu psikologi yang dikaitkan dengan doa ${ }^{6}$.

Pendapat Furniss tersebut penting diperhatikan karena, berdasarkan pengalaman, doa dalam pendampingan dan konseling pastoral yang diterapkan dengan memperhatikan perspektif ilmu psikologi sebenarnya sangat bermanfaat bagi kesehatan mental dan spiritual orang bermasalah yang dilayani. Itulah sebabnya, berdasarkan pengalaman mereka yang berdoa bagi orang sakit, yang memperhitungkan perspektif psikologi dalam pelayanan doa yang dilakukan, Evenson et.al mengatakan: "Doa berdampak pada orangpada pasien yang dilayani. Biasanya doa menyentuh dasar spiritual yang mendalam, yang sering diabaikan"7. Furniss bahkan percaya bahwa doa merupakan model pendekatan spiritual yang tidak saja berdampak secara mental dan spiritual terhadap mereka yang berdoa. Sama halnya dengan pendekatan medis, Furniss yakin bahwa Doa sebagai pendekatan spiritual, dapat meningkatkan kapasitas tubuh yang berhubungan dengan penyembuhan" ${ }^{\prime}$. Menurut penulis, pandangan Furniss ini nampaknya lahir dari kesadaran bahwa manusia merupakan mahluk multidimensional di mana berbagai dimensi dalam kehidupan manusia yakni dimensi fisik, spiritual, psikologis, dan sosial berkaitan dan saling memengaruhi dengan cara tertentu. Karenanya menjadi masuk akal jika peningkatan kualitas mental dan spiritual dalam hidup seseorang, yang terjadi melalui pelayanan doa yang bertanggungjawab, dapat berdampak positif bagi peningkatan kapasitas tubuh yang bersangkutan, yang tentu juga turut mendorong terjadinya pemulihan secara fisik.

Kebenaran dari pandangan-pandangan di atas, lebih jauh telah dibuktikan juga dalam berbagai penelitian empirik di bidang kesehatan mental di mana banyak ditemukan adanya korelasi positif antara doa dan kesehatan mental. Margaret M. Poloma dan Brian F. Pendleton dalam penelitiannya mengenai hal tersebut menyimpulkan bahwa "religiusitas dan doa berkontribusi terhadap kualitas hidup dan persepsi tentang kesejahteraan (wellbeing)" ". Kesimpulan ini diambil setelah mereka meneliti sejauhmana efektifitas empat tipe doa yakni: doa dalam bentuk percakapan sehari-hari, doa permohonan, doa ritual, dan

\footnotetext{
${ }^{6}$ Geroge. M Furniss, Healing Prayer and Pastoral Care, Journal of Pastoral Care XXXVIII. No 2 (1984): 107.

${ }^{7}$ Bruce Evenson. et.al, Prayer and Pastoral Care, The Caregiver Journal, (2014): 40.

${ }^{8}$ Geroge. M Furniss, Healing Prayer and Pastoral Care, Journal of Pastoral Care XXXVIII. No 2 (1984): 108.

${ }^{9}$ Margareth M Poloma \& Brian F. Pendleton, The Effect of prayer and Prayer Experiences on measures of General Well-Being, Journal of Psychology and Theology 19. No. 1 (1991): 81.
} 
doa meditatif, bagi kesehatan mental seseorang yang berdoa. Menurut Poloma dan Pendleton tiap tipe doa memang memiliki kelebihan dan kekurangan bagi kesehatan mental seseorang. Namun, seperti dikatakan di atas, tidak dapat dipungkiri juga bahwa doa berpengaruh positif pada kesehatan mental dari mereka yang berdoa secara tepat dan teratur $^{10}$.

Dengan demikian, dalam tulisan ini penulis akan membahas tentang bagaimana memanfaatkan doa dalam pelayanan pendampingan dan konseling pastoral, untuk mengetahui tentang praktik doa seperti apa yang diharapkan dalam pelayanan pendampingan dan konseling pastoral, sehingga hal itu dapat berguna bagi para pelaku pelayanan pastoral yang perlu memanfaatkan doa sebagai ritual dalam pelayanan yang dilakukan. Pembahasan ini dikemukakan karena, sebagaimana beberapa pendapat yang sudah dijelaskan, penulis meyakini bahwa doa adalah ritual penting dalam pelayanan pendampingan dan konseling pastoral yang jika diterapkan secara benar dan bertanggungjawab dengan sungguh-sungguh akan bermanfaat bagi perkembangan mental dan spiritual orang-orang yang dilayani. Untuk itu, penulis akan memulai pembahasan ini dengan menjelaskan mengapa doa menjadi hal yang penting dalam pendampingan dan konseling pastoral yang dilakukan. Setelah itu akan dijelaskan tentang bagaimana sebaiknya doa dimanfaatkan dalam pendampingan dan konseling pastoral, termasuk di dalamya pembahasan tentang doa seperti apa yang dibutuhkan dalam pelayanan pendampingan dan konseling pastoral.

\section{Mengapa harus berdoa?}

Sebelum membahas tentang bagaimana doa mesti dimanfaatkan dalam pelayanan pendampingan dan konseling pastoral, dibutuhkan untuk mendalami mengapa doa menjadi alat pelayanan pastoral yang harus dimanfaatkan secara bertanggungjawab dalam pendampingan dan konseling pastoral? Untuk itu, pertama-tama pembahasan ini akan menelisik beberapa gagasan terkait pengertian doa dengan melihat dari sudut pandang mereka yang berdoa. Perlu ditekankan bahwa dari sudut pandang mereka yang berdoa, doa adalah tindakan yang didasarkan pada asumsi yang sangat radikal bahwa Allah saat ini secara aktual dan aktif terlibat dengan umatnya secara individu, di mana Allah sangat mengharapkan keintiman, dan umatnya bisa merasakan keintiman itu ${ }^{11}$. Penekanan terkait

\footnotetext{
${ }^{10}$ Ibid, 78-81.

${ }^{11}$ William J Barry, Prayer in pastoral Care: A Contribution from the Tradition of Spiritual Direction. pcc.sagepub.com at University Arizona Library 11 June 2016, Diakses 28 Agustus 2019: 4.
} 
definsi doa ini penting supaya tidak jatuh pada godaan mengartikan doa hanya sebagai sebuah reaksi ataupun mekanisme psikologis, sebagaimana yang sering terjadi dalam berbagai percakapan tentang hubungan antara doa dan pendampingan pastoral.

Hal yang dimaksud dengan godaan itu nampak dalam pernyataan Evenson et.al ketika menjelaskan tentang hal yang perlu diperhatikan dalam berdoa. Evenson mengatakan: "kita sekarang mengerti bahwa doa tidak berbasis pada apa yang dapat kita antisipasi atau tidak dapat diantisipasi dari Allah. Dengan aturan ini dalam pikiran kita, doa menjadi alat aktif yang dibimbing oleh aturan pendampingan pastoral ketimbang oleh perhatian dan ketegangan teologis ${ }^{12}$. Meskipun Evenson mengatakan hal-hal itu karena ingin menekankan pentingnya doa dilihat dari segi pendekatan yang tepat dalam pelayanan pendampingan pastoral, pemahaman seperti ini jelas gagal melihat dan menerima doa sebagai sarana yang mana Allah sungguh hadir dan terlibat di dalam hidup manusia.

Oleh karena itu, menurut penulis percakapan tentang doa dari perspektif bagaimana manusia melaksanakannya tidak perlu dilakukan dengan mengecilkan keyakinan teologis terkait kehadiran dan peran Allah dalam doa yang dinaikkan manusia. Justru pengakuan tentang adanya tindakan Allah yang nyata dan aktual dalam doa yang dinaikkan manusia menuntut kita untuk memikirkan dan mempraktikkan ritual doa secara bertanggungjawab sehingga kehadiran dan peran Allah dapat dirasakan dan doa itu sendiri menjadi sebuah ritual yang bermakna serta efektif bagi mereka yang berdoa. Meminjam ungkapan Furniss, hanya dengan cara ini, Doa dapat menjadi wadah dimana hal-hal yang teologis dan pastoral saling merasuki. Tepatnya Furniss mengatakan, “...saya melihat doa sebagai titik persilangan antara teologi dan praktik pastoral kita. Sebagai seorang teolog dan pembimbing spiritual, tugas kami sebagai pendeta adalah membantu pasien, jemaat, dan klien untuk berjumpa dengan Allah dan mengalami kekuatan transformatif dalam perjumpaan itu"13.

Dengan demikin menjadi jelas bagi kita bahwa persoalannya bukan terletak pada apakah Allah hadir dan berpartisipasi atau tidak dalam doa sehingga kita harus berdoa. Justru mereka yang berdoa mesti yakin bahwa Allah sungguh hadir dan berpartisipasi dalam menyelesaikan persoalan manusia. Yang menjadi persoalan adalah pemahaman dan praktik doa di hadapan Allah sebagai Sang Entah, yang seringkali membuat seseorang justru tidak melihat dan memperoleh manfaat dalam Doa yang dilakukan.

${ }^{12}$ Bruce Evenson. et.al, Prayer and Pastoral Care, The Caregiver Journal, (2014): 41.

${ }^{13}$ Geroge. M Furniss, Healing Prayer and Pastoral Care, Journal of Pastoral Care XXXVIII. No 2 
Terkait hal itu Oliver J. Morgan mengatakan: "kita menemukan bahwa banyak orang melihat doa sebagai permintaan, untuk berpikir, untuk membuat resolusi, dan... Doa seperti ini tidak mengarah pada antusiasme yang berhubungan dengan relasi cinta yang intim" ${ }^{14}$. Jadi, menurut Morgan banyak doa yang dilakukan tidak berdampak bagi mereka yang berdoa karena mereka berfokus pada apa yang ingin mereka dapatkan dari Allah, dan pada saat yang sama justru mengabaikan keberadaan Allah sebagai pribadi yang justru menguatkan mereka yang berDoa melalui sebuah perjumpaan yang penuh cinta. Meminjam ungkapan dalam Surat Yakobus, yang menjadi persoalan dalam doa bukan doa itu sendiri. Justru yang jadi persoalan adalah motivasi dan cara-cara kita berDoa, yang membuat kita tidak memperoleh manfaat dari ritual Doa yang dilakukan (Yak 4:3).

Jika begitu, bagaimana seharunsya doa diartikan dalam konteks pendampingan dan konseling pastoral sehingga manfaat doa benar dialami oleh mereka yang berdoa? Menurut Morgan, doa dalam konteks pendampingan dan konseling pastoral harus dipahami atau diartikan sebagai sebuah respon yang bertangungjawab atas kehadiran Allah dalam doa, bukan sebuah reaksi sebagaimana umumnya dipahami. Respon yang dimaksud itu adalah respon secara keseluruhan yang meliputi pemikiran, keinginan, dan afeksi dari manusia di hadapan Allah. Sebagai sebuah respon, maka diharapkan doa dapat menjadi respon yang tepat atas keseluruhan tindakan Allah yang nyata atas diri mereka yang berdoa ${ }^{15}$. Karena itu Morgan mengatakan "Doa yang alkitabiah pertama dan terutama adalah respon terhadap Allah yang telah bertindak dan sedang bertindak, dan kita melihat bahwa orang menikmati doa ketika mereka meluangkan waktu untuk melihat dan mendengarkan hal-hal yang Allah telah lakukan. Dengan demikian kita menemukan bagi diri kita sebuah doa kontemplatif yang bernas, sebuah doa di mana seseorang melihat dan/atau mendengar karya dan perkataan Allah dan membiarkan responsnya muncul dari apa yang dilihat dan didengar"16.

Pertanyaannya adalah respon seperti apa yang diharapkan dalam doa? Untuk menjelaskan hal ini, maka secara operasional, Jordan lebih jauh mengartikan doa sebagai sebuah model komunikasi dengan otoritas menentukan yang dikenali dalam hidup seseorang. Dari sudut kita yang berdoa diharapkan agar model komunikasi yang bertanggungjawab dengan otoritas tersebut mendatangkan kebaikan spiritual bagi kita.

\footnotetext{
${ }^{14}$ Oliver J Morgan, Pastoral Counseling and Petitionary Prayer, Journal of Religion and Health 26. No. 2 (Summer, 1987): 92.

15 Ibid, 150.

16 Ibid, 92.
} 
Karena itu, Jordan mengharapkan agar dikembangkan model komunikasi yang bertanggungjawab, dalam hal berdoa.

Hal itu dikatakannya karena dalam berkomunikasi dengan Allah melalui doa seringkali orang hidup dengan berbagai gambaran yang keliru tentang Allah sebagai tujuan doa dan gambaran itulah yang mengarahkan dan mengendalikan kita dalam merespons kehadiran dan partisipasi Allah dalam doa ${ }^{17}$. Karena gambaran yang keliru tentang Allah ini pada dasarnya dihasilkan oleh sistem kepercayaan tertentu yang sebenarnya bermasalah, maka gambaran tersebut akan membawa dampak buruk bagi kita yang berdoa dalam merespon kehadiran Allah. Dikatakan demikian karena gambaran-gambaran yang keliru tentang Allah, seperti gambaran tentang Allah yang menghukum dan menuntut, membuat mereka yang merespon kehadiran Allah dalam doa justru mengalami kesulitan untuk mengungkapkan hal-hal yang sebenarnya perlu mereka nyatakan kepada Allah dalam doa, sebagai cara dengan mana mereka justru dimampukan menyikapi persoalan mereka secara bertanggungjawab.

Sebagaimana yang sudah dijelaskan, gambaran-gambaran yang keliru tentang Allah dihasilkan oleh kesalahan sistem kepercayaan yang dimiliki oleh orang-orang bermasalah yang memerlukan pendampingan dan konseling pastoral. Juga sudah dijelaskan bahwa sistem kepercayaan yang keliru itu dapat saja muncul dari pandangan-pandangan teologi operasional kita yang keliru tentang Allah. Selain itu, seperti dikatakan Jordan bahwa gambaran yang keliru tentang Allah juga seringkali bersumber dari proyeksi psikologis mereka yang berdoa.

Jordan menegaskan hal tersebut karena berdasarkan pengalamannya berDoa bersama orang-orang dengan gangguan neurosis, ternyata doa dari orang-orang tersebut seringkali diarahkan pada hal yang disebutnya sebagai berhala intrafisik yang mereka indentikan dengan Allah. Adapun yang dimaksud dengan berhala instrafisik adalah gambaran keliru orang-orang penderita neurosis tentang Allah yang membuat mereka merasa tidak nyaman dalam berkomunkasi dengan Allah melalui doa atau justru gambaran keliru tentang Allah yang membuat mereka membenarkan diri melalui proses Doa.

Jordan menyebut doa yang diarahkan pada kekeliruan tersebut sebagai doa sekuler yang membawa dampak buruk bagi mereka yang berdoa. Dikatakan demikian karena doa

${ }^{17}$ Merle Jordan, Prayer and Meditation in Pastoral Care and Counseling, Dalam Handbook for basic Types of Pastoral Care and Counseling, peny. Howard W. Stone dan William M. Clements. 129-149, (Nashville: Abingdon Press, 1991), 134. 
yakni doa sekuler yang dialamatkan pada alamat yang keliru berkorelasi dengan motivasi dan pemahaman seseorang tentang doa. Jordan mengatakan:

It is worthy of note that secular prayer to the idol tends to reinforce the power and status of the idol itself. In the fixations of persons with neurotic problems, the prayerful reaction to those suffering with neurosis of submission is to say "Amen" to the dictates of false god. Those who struggle with a neurosis of oppositions tend to react to the idol with: Hell, no!" response to the false god's directive and values. ${ }^{18}$

Menyadari hal itu, Jordan menegaskan bahwa doa yang dilakukan secara bertanggungjawab dan yang diarahkan pada Allah yang sejati, bukan kepada gambaran yang keliru tentang Allah, menjadi penting karena manusia sendiri adalah mahluk yang pusat personalitasnya terletak pada persekutuan dengan Allah. Hanya dengan model komunikasi yang benar dengan Allah yang sejati atau yang disebutnya sebagai Sang Mutlak yang sejati (True Absolute), personalitas manusia bisa dipulihkan atau diperbaiki ${ }^{19}$. Karena itu, menurut Jordan hal yang perlu diperhatikan dalam doa adalah meluruskan doa dari hati yang seringkali dialamatkan pada alamat keliru, yang menyebabkan doa tidak berfungsi secara benar dan justru menjadi bentuk pemberhalaan. ${ }^{20}$

Terkait apa yang dikatakan Jordan itu, perlu juga dicatat bahwa ada prinsip-prinsip teologis yang perlu diperhatikan dalam doa, sehingga doa dalam konteks pendampingan dan konseling pastoral, menjadi sebuah model komunikasi yang bertanggungjawab, yang menolong mereka yang berdoa agar makin matang dalam menyikapi hidup dan berbagai tantangan yang dihadapi. Bagi Furniss hal ini penting karena teologi operatif dari kita yang berdoa memainkan peranan penting dalam doa yang efektif bagi pemulihan ${ }^{21}$.

Untuk itu, Furniss kemudian menggarisbawahi hal itu dengan menegaskan beberapa presuposisi teologis yang perlu diperhatikan dalam berdoa, khususnya dalam konteks doa pemulihan. Jika memerhatikan presuposisi teologis yang dikatakan itu, terlihat bahwa Furniss ingin menegaskan secara pastoral motivasi dan doa yang benar sangat menentukan efektivitas doa yang kita lakukan. Sebagai contoh Furniss mengatakan kalau kita berdoa berdasarkan pandangan bahwa sakit yang kita alami berasal dari Allah, maka pada saat yang sama pemahaman itu justru akan membawa masalah tersendiri bagi mereka yang berdoa. Itulah sebabnya dalam uraiannya Furniss bahkan mengingatkan bahwa

\footnotetext{
${ }^{18}$ Ibid, 132.

${ }^{19}$ Ibid, 134.

${ }^{20}$ Ibid, 137.

${ }^{21}$ Geroge. M Furniss, Healing Prayer and Pastoral Care, Journal of Pastoral Care XXXVIII. No 2
} (1984): 113. 
pandangan tentang Allah sebagai sumber penyakit, merupakan pandangan yang baru muncul pada abad ke-5 dalam teologi gereja.

Sejak semula pemahaman tersebut sebenarnya tidak menjadi pandangan yang dominan karena setanlah yang dianggap sebagai sumber penyakit ${ }^{22}$. Apakah penjelasan Furniss ini tepat atau tidak tentu masih dapat diperdebatkan. Penulis berpendapat bahwa persoalannya bukan terkait apakah Allah dapat diterima sebagai yang mendatangkan penyakit bagi manusia, namun terletak pada sejauhmana kita sebagai manusia, memiliki penyerahan diri dan kesungguhan mendengar hal yang Allah katakan dan perbuat, dalam doa yang kita naikkan.

Dengan demikian menjadi jelas bagi kita, mengapa kita harus berdoa. Alasan yang pertama adalah karena Allah sendiri sebenarnya hadir dan berpartisipasi dalam doa yang kita naikkan. Kehadiran Allah inilah yang menjadi dasar bagi kita untuk sungguh-sungguh berdoa dengan cara yang dapat dipertanggungjawabkan, di mana Doa diarahkan pada alamat yang tepat, atas dasar gambaran yang benar tentang Allah. Kedua, karena kita yakin bahwa doa yang diberlakukan sebagai respons yang ditujukan kepada Allah yang sejati, membawa manfaat secara pastoral terhadap kesehatan mental dan spiritual dari mereka yang melakukan atau menjalaninya.

\section{Pemberlakuan Doa dalam Pendampingan dan Konseling Pastoral}

Setelah memahami alasan mengapa kita harus berdoa, perlu juga dibahas tentang doa dalam hubungannya dengan pendampingan pastoral. Howard Clinebell yang membahas hal ini menegaskan bahwa doa-dan juga meditasi-memainkan peranan besar dalam pendampingan atau konseling pastoral. Karena itu, Clinebell menggarisbawahi bahwa dalam pendampingan dan konseling pastoral, doa dapat dimanfaatkan untuk tiga kepentingan. Pertama, doa sangat berguna sebagai persiapan diri seorang pelaku pelayanan pastoral dalam melakukan pelayanan pendamping dan konseling pastoral. Kedua, doa perlu dipakai sebagai sarana pelayanan pastoral oleh pelaku pelayanan pastoral. Ketiga, doa juga dapat menjadi keterampilan yang diajarkan pelaku pelayanan pastoral kepada konseli atau kepada mereka yang didoakan ${ }^{23}$.

Terkait pandangan tersebut, Jordan memberikan beberapa alasan yang perlu dipertimbangkan dalam konteks konseling pastoral, yang mengharuskan seorang konselor

${ }^{22}$ Ibid, 109.

${ }^{23}$ Howard Clinebell, Tipe-Tipe Dasar Pendampingan dan Konseling Pastoral, (Jakarta \& Yogyakarta: BPK Gunung Mulia dan Kanisius, 2002): 164. 
memiliki kebiasaan doa yang benar. Menurutnya ada empat alasan yang memperlihatkan pentingnya seorang konselor berdoa dan bermeditasi. Alasan yang dimaksud itu antara lain:

a. Agar konselor waspada terhadap model komunikasi merusak dengan gambarangambaran mereka yang keliru tentang Allah, yang mungkin juga menghambat pertumbuhan atau membatasi konselor untuk memfasilitasi perkembangan yang sehat dari klien,

b. Agar konselor yang terlibat dalam supervisi, terapi personal, dan pengalaman pertumbuhan lainnya mengenali kemungkinan implikasi countertransference yang mungkin saja berakhir pada kemungkinan kolusi, jalan buntu, dan penolakan,

c. Agar konselor menyadari pola kompulsi pengulangan dalam dirinya dan dalam diri klien yang melibatkan fiksasi idolartus dan adiksi sehingga berujung pada doa dari hati yang maladaptif, dan

d. Agar konselor bisa mengalami afirmasi, validasi, dan dukungan dari dalam dirinya dan juga menemukan dalam diri kliennya sebuah model meditasi dan doa yang kreatif, yang berpusat pada hakikat Allah yang mengasihi ${ }^{24}$.

Bertolak dari penjelasan Jordan tersebut, dapat disimpulkan bahwa doa bagi seorang konselor menjadi penting karena sangat mungkin konselor sendiri memiliki pemahaman dan pengalaman yang tidak menyokong dirinya memiliki kebiasaan doa yang benar. Jika pengalaman ini diteruskan, tentu berdampak buruk bagi konselor dan juga bagi mereka yang dilayani melalui pelayanan doa yang dilakukan. Selain itu, perlu diingat bahwa dalam perjumpaan dengan klien, sangat mungkin konselor terpengaruh pemahaman dan praktik-praktik doa yang tidak mendorong kesehatan mental dan spiritual dirinya.

Selain penting bagi konselor, sebagaimana yang sudah dijelaskan, doa juga berfungsi sebagai sarana pendampingan dan konseling pastoral. Menurut penulis, pentingnya doa sebagai sarana pendampingan dan konseling pastoral berkaitan dengan dua hal. Pertama, hal ini berkaitan dengan upaya menjadikan doa sebagai titik tolak dari sebuah percakapan pastoral yang mendalam. Perlu diingat bahwa seringkali ungkapan-ungkapan paling jujur dan mendasar tentang hidup seseorang terungkap melalui doa yang diucapkan oleh yang bersangkutan. Karena itu, ungkapan-ungkapan doa dari orang yang dilayani dalam konteks pendampingan dan konseling pastoral, dapat dijadikan titik awal bagi

\footnotetext{
${ }^{24}$ Merle Jordan, Prayer and Meditation in Pastoral Care and Counseling, Dalam Handbook for basic Types of Pastoral Care and Counseling, peny. Howard W. Stone dan William M. Clements. 129-149, (Nashville: Abingdon Press, 1991): 140-141.
} 
seorang pelayan pastoral untuk memulai percakapan-percakapan yang lebih mendalam dan bermakna dengan mereka yang dilayani secara pastoral. Dengan demikian, dalam konteks pendampingan dan konseling pastoral, mereka yang dilayani perlu diajar agar mampu mengungkapkan secara jujur berbagai masalah yang mereka alami di hadapan Allah.

Selain itu, hal yang dibutuhkan dalam menanfaatkan doa sebagai sarana pelayanan pastoral adalah kemampuan seorang pendamping pastoral untuk berdoa bersama mereka yang dilayani secara pastoral. Adapun yang dimaksudkan dengan doa bersama orang yang dilayani adalah sebuah proses Doa di mana mereka yang melakukan pendampingan dan konseling pastoral tidak bertindak mengambil alih posisi sebagai Allah untuk menjawab kebutuhan dan persoalan mereka yang dilayani melalui doa yang dilakukan. Justru seorang pendamping pastoral perlu berdoa bersama dengan orang yang dilayani, dan sungguhsungguh menempatkan Allah sebagai yang sungguh berotoritas dalam menjawab doa tersebut. Karena itu, dalam konteks doa permohonan bagi orang sakit Morgan mendefinisikan posisinya itu dengan mengatakan "saya bukan 'penyembuh" yang menanggung penuh tanggungjawab yang muluk-muluk. Saya seorang kolaborator dalam proses pemulihan, bekerja bersama klien saya dan bersama Allah"25.

Karena doa adalah alat pelayanan pastoral, sebagaimana yang sudah dijelaskan, Doa juga dapat diajarkan sebagai keterampilan yang perlu dimiliki dan dipraktikan oleh orang-orang yang dilayani secara pastoral. Dengan harapan ketika yang bersangkutan memiliki kebiasaan yang benar dalam berdoa, hal itu dapat menjadi sarana pemulihan tersendiri bagi yang bersangkutan. Karena itu, dalam pendampingan dan konseling pastoral, doa perlu dijadikan jenis pekerjaan rumah bagi klien, yang mesti dilakukan secara mandiri sehingga yang bersangkutan dapat bertumbuh melalui ritual Doa yang ia lakukan secara teratur.

Persoalannnya lebih lanjut terkait doa dalam pendampingan dan konseling pastoral adalah ritual Doa yang bagaimana yang harus dipraktikan atau dimanfaatkan? Terkait hal itu beberapa teolog secara sadar menegaskan bahwa doa kontemplatif atau doa meditatif merupakan jenis doa yang diajurkan dalam pelayanan pendampingan dan konseling pastoral $^{26}$. Alasannya karena doa meditatif sangat berfungsi dalam mengarahkan pikiran-

\footnotetext{
${ }^{25}$ Oliver J Morgan, Pastoral Counseling and Petitionary Prayer, Journal of Religion and Health 26. No. 2 (Summer, 1987): 152.

${ }^{26}$ Howard Clinebell, Tipe-Tipe Dasar Pendampingan dan Konseling Pastoral, (Jakarta \& Yogyakarta: BPK Gunung Mulia dan Kanisius, 2002): 164.
} 
pikiran tak sadar, yang sering mengganggu kesehatan mental dan spiritual orang sakit ${ }^{27}$. Namun penulis tidak setuju dengan pemikiran ini, karena bukan hanya doa kontemplatif atau meditatif, tetapi semua bentuk ungkapan doa sebenarnya memiliki makna dalam konteks pendampingan dan konseling pastoral. Hal ini penulis tekankan karena Neil Pembroke dalam salah satu tulisannya yang berjudul Praying Our Anger, mengatakan bahwa rasa marah yang tidak selesai karena kemarahan yang diungkapkan dengan caracara yang tidak bertanggungjawab, akan menjadi masalah tersendiri bagi mereka yang marah pada seseorang, bahkan pada Allah ketika berdoa.

Oleh karena itu, ketika seseorang marah pada Allah disebabkan berbagai kekecewaan, maka yang bersangkutan justru mesti diajar untuk mengungkapkan kemarahan itu secara bertanggungjawab melalui doa kepada Allah, sehingga hal itu justru semakin memperkuat relasi yang bersangkutan dengan Allah dan meningkatkan kemampuannya dalam mengelola kemarahan yang dimaksud ${ }^{28}$. Dengan demikian, penjelasan Pembroke itu menunjukkan bahwa bukan hanya doa kontemplatif dan meditatif, doa lainnya seperti doa permohonan, doa sebagai sarana untuk mengungkapkan kegundahan juga berguna dalam proses pendampingan dan konseling pastoral yang dilakukan. Dalam hal ini doa yang diungkapkan dalam kekecewaan ataupun kemarahan karena berbagai situasi dapat menjadi doa yang bermanfaat secara pastoral, asalkan ungkapan kemarahan ataupun kekecewaan itu mampu dikomunikasikan dengan cara yang bertanggungjawab oleh mereka yang berdoa.

Karena itu, perlu dicatat bahwa semua jenis doa yang terekspresikan dalam konteks pendampingan dan konseling pastoral seperti doa meditatif, doa permohonan, haruslah juga merupakan Doa yang bersifat reflektif, sebagaimana umumnya dikembangkan dalam doa kontemplatif atau doa meditatif. Adapun yang dimaksud dengan doa yang reflektif, adalah model ungkapan doa di mana kita yang berdoa menyadari sepenuhnya bahwa sedang berkomunikasi dengan Allah yang mesti tetap dihargai dan dihormati sekalipun dia bersedia mendengar apapun yang menjadi keluh kesah kita. Hanya melalui ungkapanungkapan doa yang bersifat reflektif, mereka yang berDoa tidak saja memperoleh ruang untuk mengekspresikan harapan, keinginan, dan emosi, tetapi juga mendengar suara dan kehendak Allah yang juga menguatkan mereka secara mental dan spiritual. (1984): 114.

${ }^{27}$ Geroge. M Furniss, Healing Prayer and Pastoral Care, Journal of Pastoral Care XXXVIII. No 2

${ }^{28}$ Neil Pembroke, Pastoral Care in Worship: Liturgy and Psychology in Dialoque, (London: T \& T Clark International, 2010): 74-80. 
Doa yang bersifat reflektif tersebut sejatinya dapat diberlakukan dengan menggunakan berbagai cara atau teknik. Namun, David A. Hogue yang menjelaskan doa dari perspektif neuroscience mengatakan doa yang dipraktikkan dengan memanfaatkan simbol-simbol rohani sebagai sarana atau yang disebut doa kataphatik akan lebih efektif berfungsi bagi mereka yang berdoa, ketimbang doa tanpa bantuan media seperti gambar dan simbol atau yang disebut doa apofatik. Hogue menjelaskan bahwa doa dengan bantuan gambar atau simbol seperti sebuah salib atau gambar Yesus lebih merangsang fungsi imajinatif otak seseorang, sehingga doa dapat menciptakan asosiasi yang berhubungan memori, termasuk emosi. Hubungan seperti ini menolong kita membingkai ulang pengalaman-pengalaman yang tersimpan dalam memori sehingga proses pemulihan dapat terjadi $^{29}$.

Karena itu, dalam konteks pendampingan dan konseling pastoral, menurut penulis perlu diupayakan model-model doa kataphatik yang refleksif, yang menolong orang-orang yang dilayani secara pastoral dapat menemukan pemulihan secara mental dan spiritual. Inilah hal-hal yang perlu diperhatikan ketika berbicara tentang doa dalam konteks pendampingan dan konseling pastoral.

\section{Kesimpulan}

Menyadari dan mengakui bahwa Allah hadir dan berpartisipasi melalui ritual doa yang dilakukan, mengharuskan kita untuk berdoa secara benar dan bertanggungjawab. Untuk itu, dalam pelayanan pendampingan dan konseling pastoral, doa mesti dimengerti sebagai sebuah respon manusia, yang mengandaikan adanya sebuah model komunikasi yang tepat dengan Allah yang sejati sebagai tujuan doa yang benar. Selanjutnya, bertolak dari pengertian doa sebagai respons maka seorang pelayan pastoral harus mampu melihat manfaat ritual Doa bagi dirinya dan bagi orang yang dilayani dalam melakukan pendampingan dan konseling pastoral. Karena itu, dalam pelayanan pendampingan dan konseling pastoral, doa untuk mereka yang dilayani secara pastoral mesti diberlakukan sebagai doa bersama dengan orang yang dilayani di hadapan Allah. Doa yang dimaksud adalah Doa reflektif, khususnya yang bersifat katphatik.

${ }^{29}$ David A Hoque, Remembering the Future, Imagining the Past: Story, Ritual, and the Human Brain, (Cleveland: The Pilgrim Press, 2003): 192-193. 


\section{Kepustakaan}

Asquith, Gleen H. The Concise Dictionary of Pastoral Care and Counseling, Nashville: Abingdon Press, s.v. Biblical Pastoral Care and Counseling (S.D.King), 2010.

Barry, William J. Prayer in pastoral Care: A Contribution from the Tradition of Spiritual Direction. pcc.sagepub.com at Univ. Arizona Library 11 June 2016. Diakses 28 Agustus 2019.

Benner, David G. Strategic Pastoral Counseling: A Short Term Stuctured Model, $2^{\text {nd }}$ ed. Grand Rapids-Michingan: Baker Academic, 2003.

Clinebell, Howard. Tipe-Tipe Dasar Pendampingan dan Konseling Pastoral. Jakarta \& Yogyakarta: BPK Gunung Mulia dan Kanisius, 2002.

Evenson, Bruce et.al. Prayer and Pastoral Care. The Caregiver Journal, (2014): 40-47.

Furniss, Geroge. M. Healing Prayer and Pastoral Care. Journal of Pastoral Care XXXVIII, No 2 (1984): 107-119.

Hoque, David A. Remembering the Future, Imagining the Past: Story, Ritual, and the Human Brain. Cleveland: The Pilgrim Press, 2003.

Jordan, Merle. Prayer and Meditation in Pastoral Care and Counseling. Dalam Handbook for basic Types of Pastoral Care and Counseling, peny. Howard W. Stone dan William M. Clements, 129-149. Nashville: Abingdon Press, 1991.

Morgan, Oliver J. Pastoral Counseling and Petitionary Prayer. Journal of Religion and Health 26, No. 2 (Summer, 1987): 149-152.

Pembroke, Neil. Pastoral Care in Worship: Liturgy and Psychology in Dialoque. London: $\mathrm{T} \& \mathrm{~T}$ Clark International, 2010.

Poloma, Margareth M \& Brian F. Pendleton. The Effect of prayer and Prayer Experiences on measures of General Well-Being. Journal of Psychology and Theology 19, No. 1 (1991): 71-83. 